\title{
An examination of the clonal variants of Serratia marcescens that infect the eye during contact lens wear
}

\author{
E. B. H. HUME, M. D. P. WILLCOX, D. F. SWEENEY and B. A. HOLDEN \\ Cooperative Research Centre for Eye Research and Technology, University of New South Wales, NSW 2052, \\ Australia
}

\begin{abstract}
Serratia marcescens colonises contact lenses during wear, although the frequency of isolation is generally low $(0.6 \%$ contamination rate). A method for typing the $S$. marcescens colonising the eye or contact lens was developed, based upon ribotyping, serotyping and biotyping. Twelve different types of $S$. marcescens were isolated from the eyes, contact lenses, contact lens cases and fingers of contact lens wearers in the Sydney area over a 2-year period. There was no evidence of a specific type being more readily able to colonise the contact lenses than other types. Indeed, eight $S$. marcescens strains were isolated from the lenses and these belonged to seven types. The diversity of types isolated from the eye indicates that there is probably not a subset of $S$. marcescens that can colonise the eye, although the results suggest that the types of strains isolated from contact lenses are different from those isolated from nosocomial infections.
\end{abstract}

\section{Introduction}

Serratia marcescens is an opportunist pathogen that has been implicated in a variety of nosocomial infections including septicaemia, urinary tract infections and meningitis [1]. S. marcescens has also been implicated in ocular infections such as keratoconjunctivitis [2], endophthalmitis [3] and keratitis [4] - all of which may be associated with loss of vision if not treated properly - and an inflammation reaction called 'contact lensinduced acute red eye' (CLARE) in which $S$. marcescens has been cultured in large numbers from $24 \%$ of lenses at the time of an event [5]. CLARE occurs in $7 \%$ of contact lens wearers per annum, is one of the major reasons for the discontinuation of wearing lenses and occurs specifically during the overnight extended wear of contact lenses. The symptoms of CLARE are acute pain, corneal infiltration, lachrymation, photophobia and reddening of the conjunctiva [6].

Various methods have been used to type nosocomial strains of $S$. marcescens, including biotyping [7,8], serotyping, antibiograms [9], phage typing [10] and bacteriocin production and susceptibility [9]. These methods lack sensitivity, can be costly and may require lengthy periods of time to perform [11]. The Grimont biotyping system has been modified by

Received 6 June 1995; revised version accepted 8 Jan. 1996. Corresponding author: Dr E. B. H. Hume.
Sifuentes-Osornio et al. [12] and although this method is sensitive, molecular methods are needed to subdivide strains further.

There are various molecular typing methods available, including protein fingerprinting [13], zymotyping [14], plasmid analysis $[15,16]$, restriction endonuclease analysis [13] and ribotyping. In previous reports, protein fingerprinting appeared to lack sufficient sensitivity to distinguish between isolates [13]. Gargallo-Viola [14] found that zymotyping (the analysis of different enzymes) was sensitive enough to subdivide isolates, but the zymotypes did not correlate with the pathogenicity of strains. McGeer et al. [13] used restriction endonuclease analysis (REA) to type nosocomial isolates of $S$. marcescens. This method was sensitive, but it was difficult to distinguish strains due to the large number of fragments generated. Ribotyping has been used to type hospital strains [10, $17,18]$. This method was shown to be effective in discriminating between isolates; the results were easier to interpret that REA and enabled the investigators to track the spread of infection and sites of colonisation of $S$. marcescens. The types of $S$. marcescens that colonise contact lenses have not yet been determined. In nosocomial infections specific types of $S$. marcescens have been implicated in disease. The majority of isolates are non-pigmented [14], at least $24 \%$ of nonpigmented strains contain plasmids $[14,15]$ and the majority of isolates are of serotype O14 $[8,18]$.

The aim of this study was to develop an effective 
method to discriminate between $S$. marcescens strains and to use this method to determine the range of clonal variants of $S$. marcescens that colonise the eye during contact lens wear.

\section{Materials and methods}

\section{Patient details}

Seventy subjects participated in the study, which was conducted at the Cornea and Contact Lens Research Unit, School of Optometry, University of New South Wales, Sydney, Australia. Twenty-six subjects used soft hydrogel contact lenses on a daily wear basis and 44 on an extended wear basis. All subjects were free of ocular and systemic disease, had had no previous ocular surgery, and required visual correction for low refractive errors only. Informed consent was obtained before lenses were fitted.

The base materials of the lenses used were etafilcon A (Vistakon, Johnson and Johnson, Jacksonville, FL, USA), a $58 \%$ water content ionic hydrogel material, and polymacon (Bausch and Lomb, Rochester, NY, USA), a $38 \%$ water content non-ionic hydrogel material. A different lens type was worn in each eye and lenses were allocated randomly. Extended wear lenses were worn on a schedule of 6 nights per week continuously, with lenses replaced weekly. Daily wear users replaced lenses fortnightly.

Lenses from outside practitioners $(n=4)$ were also sent to this laboratory for culturing, these patients wore their lenses on either a daily wear or extended wear basis.

\section{Determination of carriage of $S$. marcescens on the ocular surface, contact lenses, contact lens cases and fingers of subjects}

The microbial flora of the lids and conjunctiva was sampled before lens fitting as a baseline and subsequent sampling together with the contact lenses was performed after $1,3,6,9$ and 12 months of wear. Ocular sites were samples with calcium alginate swabs moistened with sterile saline. Samples were taken from the upper bulbar conjunctiva, with avoidance of contact with the lids, lashes and tarsal conjunctiva. A second swab was passed along the lower lid margin, with avoidance of contact with the bulbar conjunctiva and lashes. Swabs were placed immediately into $2 \mathrm{ml}$ of sterile phosphate-buffered saline (PBS; $\mathrm{NaCl} 8 \mathrm{~g} / \mathrm{L}$, $\mathrm{KCl} 0.2 \mathrm{~g} / \mathrm{L}, \mathrm{Na}_{2} \mathrm{HPO}_{4} 1.15 \mathrm{~g} / \mathrm{L}, \mathrm{KH}_{2} \mathrm{PO}_{4} 0.2 \mathrm{~g} / \mathrm{L}$ ) and vortex mixed for $30 \mathrm{~s}$. After removal of the swab, a 0.4-ml sample was used to inoculate a chocolate agar plate (Becton Dickinson, North Ryde, Sydney, Australia). The plate was incubated aerobically at $35^{\circ} \mathrm{C}$ and read after incubation for $48 \mathrm{~h}$.

For enumeration of $S$. marcescens on contact lenses (after 1, 3, 6, 9 and 12 months of wear), the contact lens was removed aseptically with sterile gloves and placed in a bottle containing $2 \mathrm{ml}$ of sterile PBS. The lens was then removed, placed concave side down on a chocolate agar plate, covered in $10 \mathrm{ml}$ of sterile nutrient agar and incubated in air $+\mathrm{CO}_{2} 5 \% \mathrm{v} / \mathrm{v}$ for $24 \mathrm{~h}$ at $35^{\circ} \mathrm{C}$. The PBS was also examined for bacterial contamination by plating $200 \mu \mathrm{l}$ on a chocolate agar plate and incubating for $24 \mathrm{~h}$ at $35^{\circ} \mathrm{C}$.

Contamination of lens cases was measured by vigorously swabbing lens cases with a dry calcium alginate swab. The swab was then processed according to the protocol for ocular swabs (see above). The swab was dry prior to sampling as the cases contained up to $500 \mu \mathrm{l}$ of liquid. Contamination of subjects' fingers was assessed by asking the subjects to press gently all four fingers and thumb of each hand on to a chocolate agar plate. The plate was then incubated for $48 \mathrm{~h}$ at $35^{\circ} \mathrm{C}$.

After incubation of all agar plates, colonies were streaked for purity. Gram-negative, oxidase-negative rods were counted and identified with API 20E test kits (Vitek, Baulkham Hills, Australia).

\section{Biotyping}

Production of pigment was examined after growth aerobically at $35^{\circ} \mathrm{C}$ for $18 \mathrm{~h}$ on peptone (Difco, Michagen, USA) $0.5 \% \mathrm{w} / \mathrm{v}$, glycerol (BDH, Kilsyth, VIC) $1 \% \mathrm{v} / \mathrm{v}$ agar by examining colonies for pink colouration. Strains were biotyped, three times for each isolate, with API 20E strips (Vitek) according to the manufacturer's instructions. API $20 \mathrm{E}$ comprises 23 biochemical tests to characterise bacteria from the family Enterobacteriaceae (Table 1).

\section{Serotyping}

The strains were serotyped with 'Seiken' Serratia-Ogrouping immune sera kit (Accurate Chemical and Scientific Corp, Westbury, NY, USA) according to the manufacturer's instructions. Briefly, bacterial antigen was generated by heating a bacterial suspension, which was prepared by emulsifying all bacterial colonies

Table 1. Differentiation of biotypes based on biochemical tests

\begin{tabular}{lcccc}
\hline $\begin{array}{l}\text { Biotype } \\
\text { no. }\end{array}$ & $\begin{array}{c}\text { Galactosidase } \\
\text { production }\end{array}$ & $\begin{array}{c}\text { Urease } \\
\text { production }\end{array}$ & $\begin{array}{c}\text { Indole } \\
\text { production }\end{array}$ & $\begin{array}{c}\text { Arabinose } \\
\text { fermentation }\end{array}$ \\
\hline 1 & + & - & - & + \\
2 & + & + & - & + \\
3 & + & - & - & - \\
4 & - & + & - & - \\
5 & + & - & + & + \\
\hline
\end{tabular}


grown on a chocolate agar slant (incubated at $35^{\circ} \mathrm{C}$ for $18 \mathrm{~h}$ ) in $10 \mathrm{ml}$ of saline, at $120^{\circ} \mathrm{C}$ for $20 \mathrm{~min}$. The suspension was then cooled and centrifuged. The pellet was weighed, resuspended to $10 \mathrm{mg}$ of protein $/ \mathrm{ml}$, then mixed with the $\mathrm{O}$ antisera and incubated at $50^{\circ} \mathrm{C}$ for $2 \mathrm{~h}$. After incubation overnight at $5^{\circ} \mathrm{C}$, the tubes were observed and the presence of agglutination was considered positive.

\section{DNA extraction and separation of fragments}

All products for ribotyping were obtained from Boehringer (Mannheim, Germany) unless otherwise stated. Growth from overnight broth cultures in trypticase soy broth (TSB) was harvested by centrifugation, washed and resuspended in $10 \mathrm{ml}$ of $50 \mathrm{mM}$ Tris- $\mathrm{HCl}$, $\mathrm{pH} 8.0 ; 400 \mu \mathrm{l}$ of $0.5 \mathrm{M}$ EDTA was then added and incubated for $10 \mathrm{~min}$ at $37^{\circ} \mathrm{C}$. Cells were lysed by the addition of $400 \mu \mathrm{l}$ of lysozyme (Sigma) $20 \mathrm{mg} / \mathrm{ml}$ and incubated at $37^{\circ} \mathrm{C}$ for $10 \mathrm{~min}$. After incubation, $400 \mu \mathrm{l}$ of SDS $10 \%$ was added to further lyse the bacteria and $10 \mu \mathrm{l}$ of RNAase A $10 \mathrm{mg} / \mathrm{ml}$ and $25 \mu \mathrm{l}$ of proteinase $\mathrm{K} 20 \mathrm{mg} / \mathrm{ml}$ were added. This mixture was incubated at $37^{\circ} \mathrm{C}$ for $1 \mathrm{~h}$. DNA was purified by three phenol: chloroform:isoamyl alcohol (25:24:1) extractions and precipitated with a 1 in 10 volume of $3 \mathrm{M}$ sodium acetate ( $\mathrm{pH} 5.5)$ and 2 volumes of ice-cold ethanol $100 \%$. DNA was spooled on to a hooked-end pasteur pipette, washed in ethanol $70 \%$, dried and resuspended in TE buffer ( $10 \mathrm{mM}$ Tris-HCl, $1 \mathrm{mM}$ EDTA, $\mathrm{pH}$ 8.0). The DNA yield and purity was determined by measuring the optical density at $260 \mathrm{~nm}$ and $280 \mathrm{~nm}$ [19]. Before digestion with restriction endonucleases, DNA was subjected to agarose gel electrophoresis (see below) and stained with ethidium bromide to examine for the presence of plasmids.

Purified DNA $(20 \mu \mathrm{g})$ was digested with Eco RI and Bam HI according to the manufacturer's instructions. The digests were analysed by gel electrophoresis at $30 \mathrm{~mA}$ for $18 \mathrm{~h}$ through agarose $0.7 \%$ gels containing ethidium bromide $0.5 \mu \mathrm{g} / \mathrm{ml}$ in TBE buffer $(0.089 \mathrm{M}$ Tris-base, $0.089 \mathrm{M}$ boric acid and $2 \mathrm{mM}$ EDTA, $\mathrm{pH}$ 8.0). After electrophoresis, Southern transfers [19] of the gels were performed by blotting to nitrocellulose membranes (Hybond- $\mathrm{N}^{+}$, Amersham, North Ryde, NSW, Australia).

\section{Preparation of probe and hybridisation}

A cDNA probe was made from Escherichia coli $16 \mathrm{~S}$ and 23S RNA with AMV reverse transcriptase and a mixture of hexanucleotides in the presence of digoxigenin-11-dUTP (DIG-11-UTP) according to the manufacturer's instructions (Boehringer). The membranes were hybridised overnight at $68^{\circ} \mathrm{C}$ in $5 \times \mathrm{SSC}$ buffer $(750 \mathrm{mM} \mathrm{NaCl}, 75 \mathrm{mM}$ sodium citrate, $\mathrm{pH} \mathrm{7.0)}$, blocking reagent $1 \%$, N-lauroylsarcosine $0.1 \%$, SDS $0.02 \%$ and DIG-labelled cDNA to a final concentration of $5-25 \mathrm{ng} / \mathrm{ml}$. Chemiluminescence was detected with an anti-DIG-alkaline phosphatase-conjugated antibody and the substrate Lumigen ${ }^{\mathrm{TM}}$ PPD according to the manufacturer's instructions. The membranes were autoradiographed by exposure to photographic film (Amersham) overnight at $-70^{\circ} \mathrm{C}$.

\section{Results \\ Microbial contamination of contact lenses, ocular sites, lens cases and subjects fingers}

Contamination of ocular surfaces and devices with $S$. marcescens was rare. No $S$. marcescens strains were isolated from the lid swabs. However, conjunctival swabs showed a $0.16 \%$ contamination rate $(625$ sampling occasions). Contact lenses showed a $0.6 \%$ contamination rate (1427 sampling occasions). Contact lens cases showed the highest contamination rate of $1 \%$ (211 sampling occasions) and fingers showed a contamination rate of $0.5 \%$ (203 sampling occasions). There were no significant differences between the contamination rates of any of the surfaces sampled.

Contact lenses gave the greatest number of cfu (median $>300$; range $1->300$ ), the lens case gave the next highest level of contamination (median 36 cfu; range 8-65), the conjunctiva gave the next highest level of contamination (median $4 \mathrm{cfu}$; range 3-10) and the fingers gave the lowest level of contamination ( 3 cfu). For only one patient was $S$. marcescens isolated from more than one site; this strain was isolated from both the conjunctiva and the lens.

There was a tendency for a greater rate of isolation from patients on a daily wear lens schedule (23\%) than from those on extended wear $(9 \%)$. However, by the proportions test this was not significantly different. There was no difference in isolation rate from Etafilcon or Polymacon lens types.

\section{Strains}

Sixteen $S$. marcescens isolates were examined; 11 of these were isolated from the lenses or conjunctiva of asymptomatic patients, two from lens cases, one from fingers and one from a contact lens at the time of a CLARE event. Type strain ATCC 274 was used for comparative purposes. Isolates were divided into 13 types based on differences in their biotypes, serotypes and ribotypes (Table 2 ).

\section{Biochemical characterisation}

The only strain that was pigmented was ATCC strain 274; all clinical isolates were non-pigmented. API $20 \mathrm{E}$ biotypes were defined by the characteristic number assigned by the manufacturer to describe a bacterial strain's ability to ferment carbohydrates and produce several other enzymic reactions. The differences in reactions between biotypes are shown in Table 1 . Five 
Table 2. Source, serotype, biotype and ribotype of various $S$. marcescens strains

\begin{tabular}{|c|c|c|c|c|c|c|}
\hline Isolate no. & Isolation site & Date of isolation & Serotype* & Biotype $^{\dagger}$ & Ribotype ${ }^{\ddagger}$ & Type $^{\S}$ \\
\hline Smar 5 & CLARE, lens & June 1991 & $0: 13$ & 1 & 1 & 1 \\
\hline Smar 7 & Conjunctiva & June 1991 & $0: 13$ & 1 & 1 & 1 \\
\hline Smar9 & Lens & May 1992 & $0: 13$ & 1 & 1 & 1 \\
\hline Smarl2 & Lens & March 1993 & $0: 13$ & 1 & 2 & 2 \\
\hline Smar12b & Conjunctiva & March 1993 & $0: 13$ & 1 & 2 & 2 \\
\hline ATCC 274 & $\ldots$ & Type strain & $\mathrm{O}: 6$ & 5 & 2 & 3 \\
\hline Smarl & Lens & Nov. 1992 & O:5 & UT & 3 & 4 \\
\hline Smar4 & Lens & May 1992 & UT & 3 & 3 & 5 \\
\hline Smar 11 & Conjunctiva & Nov. 1992 & UT & 1 & 3 & 6 \\
\hline Smarl3 & Case & June 1993 & $\mathrm{O}: 13$ & 2 & 4 & 7 \\
\hline Smar14 & Conjunctiva & June 1993 & $O: 14$ & 2 & 4 & 8 \\
\hline Smar2 & Lens & Aug. 1992 & O:6 & 3 & 5 & 9 \\
\hline Smar3 & Lens & Feb. 1992 & UT & 4 & 6 & 10 \\
\hline Smar6 & Lens & Sep. 1991 & UT & 1 & 7 & 11 \\
\hline Smar15 & Fingers & June 1993 & $0: 5$ & UT & 8 & 12 \\
\hline Smar17 & Case & Oct. 1993 & $0: 16$ & 2 & 9 & 13 \\
\hline
\end{tabular}

UT, untypable.

* Serology was performed on whole cells with commercially available antisera.

${ }^{\dagger}$ Biotyping differentiated strains on five key biochemical tests (Table 1).

${ }^{\ddagger}$ Ribotyping was performed by digesting chromosomal DNA with restriction enzyme Eco RI (Fig. 1).

${ }^{\S}$ The final 'type' for each strain was based on similarities in biotype, serotype and ribotype.

biotypes were generated with API 20E (Table 2). The biotypes were determined by testing strains on three different occasions. Sometimes the biotype varied and so was assigned a type when a minimum of two of three tests gave consistent results. The exceptions to this rule were isolates Smarl and Smar15 which gave variable results and, therefore, were classified as untypable.

\section{Serotyping}

The isolates fell into five serotypes $(13,14,5,6$ and $16)$, the most common of these being serotype 13 (Table 2). There was generally a good correlation between serotype $\mathrm{O} 13$ and biotype 1 (Table 2). However, strains of serotype O6 were divided between biotypes 5 and 3 . With our antisera $25 \%$ of the isolates showed no agglutination reaction with the antisera and so were classed as untypable.

\section{DNA analysis and ribotyping}

No strain was shown to possess plasmid DNA. After digestion with the restriction endonuclease Eco RI probing with labelled $16 \mathrm{~S}$ and $23 \mathrm{~S}$ rRNA, nine distinct ribotypes were found (Fig. 1, Table 2). A ribotype was defined as a distinct pattern of banding. The most common ribotypes were ribotypes 1 and 2, representing $22 \%$ of isolates each. Serotype 13 and ribotype 1 was the most common combination; the isolate from a CLARE episode fell into this group. Serotype 13 and ribotype 2 was also a common combination and this was an internal control as two strains (Smar12 and 12b) from the same patient isolated on the same day from different sites fell into this group. With Bam HIdigested chromosomal DNA, no differences between isolates could be discerned.

\section{Discussion}

This study has developed a rapid typing scheme for $S$. marcescens based on the genetic and physiological diversity of these strains. $S$. marcescens has been found to cause corneal infections related to the wearing of contact lenses which may be due to colonisation of the lenses by bacteria. This study demonstrated that many different types of $S$. marcescens are able to colonise the eye during contact lens wear.

The diversity of types isolated from the eye indicates that there is probably not a subset of $S$. marcescens that can colonise the eye. Similarly, to the majority of nosocomial isolates $[20,21]$ all ocular isolates proved to be non-pigmented, although the significance of this is not known. Six of the 15 isolates were of serotype of O13. In comparison, none of 209 strains was 013 in a study conducted by Alonso et al. [18] and only one of 117 strains in the study by Rubin et al. [8]. These results are very different from nosocomial studies where $\mathrm{O} 14$ is the major serotype isolated $[8,18]$, whereas only one of 15 strains belonged to this serotype in the present study. Simor et al. [15] and John and McNeill [16] used plasmid analysis to type nosocomial strains of $S$. marcescens. However, this method was not suitable for the present study, as none of the strains so far isolated from contact lenses has contained plasmids. John and McNeill [16] found that $92 \%$ of nosocomial strains contained plasmids. Our strains may not contain plasmids due to the lack of selection pressure. The serotyping results combined with the lack of plasmids suggest that $S$. marcescens strains that colonise the contact lens are community acquired and distinct from nosocomial strains.

The preponderance of serotype $\mathrm{O} 13$ in this study is of 


\section{6}

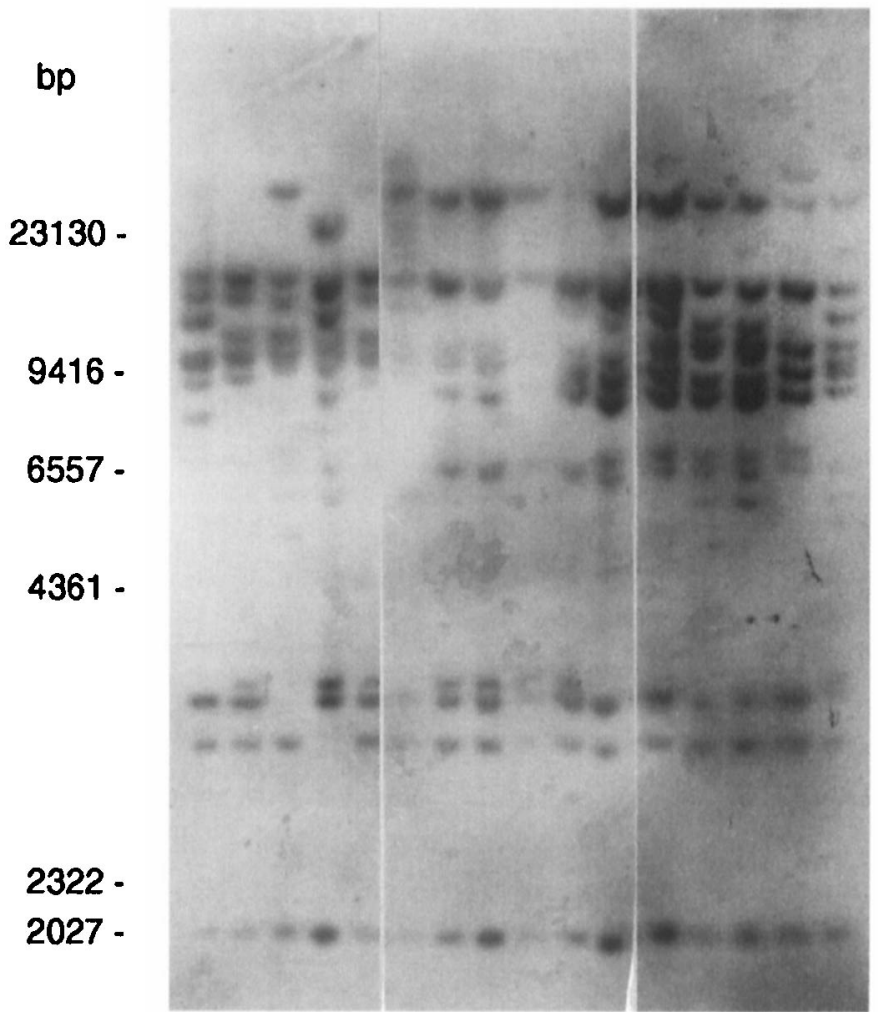

Fig. 1. Ribotyping of $S$. marcescens. Chromosomal DNA from each $S$. marcescens isolate was digested with Eco RI and separated by agarose gel electrophoresis. Lane 1, ATCC 274; 2, Smar 1; 3, Smar 2; 4, Smar 3; 5, Smar 4; 6, Smar 6; 7, Smar 7; 8, Smar 5; 9, Smar 9; 10, Smar 11; 11, Smar 12; 12, Smar 12b, 13, Smar 13; 14, Smar 14; 15, Smar 15; 16, Smar 17.

interest. There is some evidence that the O13 serotype antigen is not lipopolysaccharide but an acidic polymer [22]. The 013 serotype has been reported to be a rough phenotype [22]. However, the colony morphology of strains in the present study does not suggest a correlation between $\mathrm{O} 13$ serotype and roughness.

Grimont and Grimont [7] have developed a sensitive biotyping system. However, this method is time consuming (requiring up to 14 days for measuring utilisation of carbon sources) and labour intensive. The systems used in the present study were a commercially available biochemical test kit, a commercially available serotyping kit and a rapid analysis for restriction endonuclease fragment patterns of chromosomal DNA with Eco RI. Eco RI gave an adequate number of bands to distinguish between strains, as was found also by Alonso et al. [18]. To determine the type of each $S$. marcescens isolate only 4 days were required from first isolating the strain from the eye in the present typing scheme. Thus the present system was quicker than the system of Grimont and Grimont [7]. In view of the large number of fragments generated by restriction endonuclease analysis, the development of a ribotyping system allowed a more reliable comparison of a large number of strains.
$S$. marcescens grows well in moist environments, and solutions and damp surfaces have been implicated as reservoirs in several nosocomial outbreaks [23-25]. However, more recent evidence [13] has shown that $S$. marcescens strains colonising children in hospital are not commonly acquired from the environment, but colonise the pharynx secondarily to rectal colonisation. Furthermore, hand wash cultures of hospital staff were negative [13]. In the present investigation, the single isolate from the fingers of a lens wearer possessed a unique ribotype (type 6) that was not represented in the isolates from contact lensses or conjunctiva. This, albeit preliminary evidence from a small number of isolates, suggests that the route of contamination of eye or contact lenses is not via hands.

The source of colonisation of contact lenses by Pseudomonas aeruginosa strains that have caused corneal ulceration has been traced by Mayo et al. [26] with various methods including serotyping and plasmid profiling. They demonstrated that an isolate from the cornea was identical to that found in the saline solution from the same patient. In the present investigation, there were two isolates from contact lens cases but these were of unique types.

In the future, typing of isolates from environmental sources such as water and from symptomatic patients 
by this method would enable the source of contamination of contact lenses to be traced. This method may define specific pathogenic types of $S$. marcescens and enable development of strategies to prevent contact lens contamination.

\section{References}

1. Von Graevenitz A. Human disease due to Serratia. In: Von Graevenitz A, Rubin SJ (eds) The genus Serratia. Boca Raton, Florida, CRC Press. 1980: 67-186.

2. Atlee WE, Burns RP, Oden M. Serratia marcescens keratoconjunctivitis. Am J Ophthalmol 1970; 70: 31-33.

3. Salceda SR, Lapuz J, Vizconde R. Serratia marcescens endophthalmitis. Arch Ophthalmol 1973; 89: 163-166.

4. Lass JH, Haaf J, Foster CS, Belcher C. Visual outcome in eight cases of Serratia marcescens keratitis. Am J Opthalmol 1981; 92: 384-390.

5. Holden BA, La Hood D, Grant $\mathrm{T}$ et al. Gram-negative bacteria can induce contact lens-related acute red eye (CLARE) responses. CLAO J (in press).

6. Grant T, Terry R, Holden BA. Extended wear of hydrogel lenses: clinical problems and their management. In: Harris MG (ed) Problems in optometry. Philadelphia, JB Lippincott. 1990: 599-622.

7. Grimont PAD, Grimont F. Biotyping of Serratia marcescens and its use in epidemiological studies. J Clin Microbiol 1978; 8: $73-83$.

8. Rubin SJ, Brock S, Chamberland M, Lyons RW. Combined serotyping and biotyping of Serratia marcescens. $J$ Clin Microbiol 1976; 3: 582-585.

9. Larose P, Picard B, Thibault M, Grimont F, Goullet P. Nosocomial Serratia marcescens individualized by five typing methods in a regional hospital. J Hosp Infect 1990; 15: 167172.

10. Pitt TL, Erdman YJ, Bucher C. The epidemiological type identification of Serratia marcescens from outbreaks of infection in hospitals. $J$ Hyg 1980; 84: 269-283.

11. Bale M, Sanford M, Hollis R, Pfaller MA. Application of a biotyping system and DNA restriction fragment analysis to the study of Serratia marcescens from hospitalized patients. Diagn Microbiol Infect Dis 1993; 16: 1-7.

12. Sifuentes-Osornio J, Ruiz-Palacios GM, Gröschel DHM. Analysis of epidemiologic markers of nosocomial Serratia marcescens isolates with special reference to the Grimont biotyping system. J Clin Microbiol 1986; 23: 230-234.

13. McGeer A, Low DE, Penner J, Ng J, Goldman C, Simor AE Use of molecular typing to study the epidemiology of Serratia marcescens. J Clin Microbiol 1990; 28: 55-58.

14. Gargallo-Viola D. Enzyme polymorphism, prodigiosin production, and plasmid fingerprints in clinical and naturally occurring isolates of Serratia marcescens. J Clin Microbiol $1989 ; 27: 860-868$.

15. Simor AE, Ramage L, Wilcox L, Bull SB, BialkowskaHobrzanska H. Molecular and epidemiologic study of multiresistant Serratia marcescens infections in a spinal cord injury rehabilitation unit. Infect Control 1988; 9: 20-27.

16. John JF, McNeill WF. Characteristics of Serratia marcescens containing a plasmid coding for gentamicin resistance in nosocomial infections. J Infect Dis 1981; 143: 810-817.

17. Bingen EH, Mariani-Kurkdjian P Lambert-Zechovsky NY et al. Ribotyping provides efficient differentiation of nosocomial Serratia marcescens isolates in a pediatric hospital. J Clin Microbiol 1992; 30: 2088-2091.

18. Alonso R, Aucken HM, Perez-Diaz JC, Cookson BD, Baquero F, Pitt TL. Comparison of serotype, biotype and bacteriocin type with rDNA RFLP patterns for the type identification of Serratia marcescens. Epidemiol Infect 1993; 111: 99-107.

19. Sambrook J, Fritsch EF, Maniatis T. Molecular cloning; a laboratory manual, 2nd edn. Cold Spring Harbor, NY, Cold Spring Harbor Laboratory Press. 1989.

20. Davis JT, Foltz E, Blakemore WS. Serratia marcescens. A pathogen of increasing importance. JAMA 1970; 214: 2190 2192.

21. Alexander S, Pinck BD, Petzall G. Serratia marcescens infections. J Med Soc New Jersey 1970; 67: 261-263.

22. Gaston MA, Pitt TL. C-antigen specificities of the serotype strains of Serratia marcescens. J Clin Microbiol 1989; 27: 2697-2701.

23. Anagnostakis D, Fitsialos J, Koutsia C, Messaritakis J, Matsaniotis N. A nursery outbreak of Serratia marcescens infection. Evidence of a single source of contamination. Am J Dis Child 1981; 135: 413-414.

24. Maki DG, Hennekens CG, Phillips CW, Shaw WV, Bennett JV. Nosocomial urinary tract infection with Serratia marcescens: an epidemiological study. $J$ Infect Dis 1973; 128: 579-587.

25. Yu VL. Serratia marcescens. Historical perspective and clinical review. $N$ Engl J Med 1979; 300: 887-893.

26. Mayo MS, Cook WL, Schlitzer RL, Ward MA, Wilson LA, Ahearn DG. Antibiograms, serotypes, and plasmid profiles of Pseudomonas aeruginosa associated with corneal ulcers and contact lens wear. J Clin Microbiol 1986; 24: 372-376. 